\title{
Six in $\mathbf{1 0}$ doctors in Scotland plan to vote against independence
}

Clarification-On 13 August, The BMJ published the results of a poll that it had undertaken of 2297 doctors in Scotland (BMJ 2014;349:g5072, doi:10.1136/bmj.g5072), asking them which way they intended to vote in the Scottish referendum. A total of 311 doctors voted, a response rate of $14 \%$. It showed that 185 doctors planned to vote "no" to independence, 104 planned to vote "yes," and 20 were undecided.

The News story made it clear that it was "a snapshot survey" and it was completely transparent about the methods used. It did not present the results as a piece of research.
However, The BMJ now realises that the headline did not reflect the restricted nature of the survey. We now feel that, with hindsight, the headline should have read: "A BMJ survey indicates that six in 10 doctors in Scotland may vote against independence."

Cite this as: BMJ 2014;349:g6224

๑ BMJ Publishing Group Ltd 2014 